\title{
Lazer, Turismo e Espaço Urbano: a reconversão portuária na cidade de Santa Fé, Argentina
}

\section{Leisure, Tourism and Urban Space: the port reconversion in the city of Santa Fé, Argentina}

\author{
El Ocio, el Turismo y el Espacio Urbano: la conversión del puerto en la ciudad de \\ Santa Fe, Argentina
}

Jéssika Paiva França ${ }^{1}$

\begin{abstract}
Resumo
Este artigo é resultante de um estágio realizado no ano de 2014 na Universidade Nacional del Litoral, na cidade de Santa Fé na Argentina em parceria com a Universidade de São Paulo e financiamentoda instituição SANTANDER. Tem como objetivo, o estudo da área portuária da cidade de Santa Fé que foi transformada em um complexo de lazer e turismo seguindo uma tendência internacional de reconfiguração de espaços waterfronts (frente de águas). A metodologia envolveu pesquisa bibliográfica e realização de entrevista semiestruturada junto à secretaria de planejamento urbano da cidade. Os resultados apontam que a área portuária no ano de 2004 passou por um processo de reconversão de suas funções, objetivando o atendimento a uma política de planejamento estratégico de cidade, em busca da retomada do papel de centralidade. Ao seu término é traçada uma reflexão sobre a postura assumida pelos gestores públicos na cidade contemporânea e o peso destinado a atividade turística enquanto viés de desenvolvimento econômico local. A reconversão portuária em Santa Fé está baseada em um modelo internacional de planejamento urbano e utilização de espaços em frentes de água para fins de lazer e turismo, viabilizados através deparceria estabelecida entre os setores público e o privado.
\end{abstract}

Palavras-chave: Espaço; Planejamento Urbano; Área portuária; Frente de água; Lazer e turismo.

\section{Abstract}

This article is a result of an internship in 2014 at the Universidad Nacional del Litoral in Santa Fe - Argentina, in partnership with the University of São Paulo, and financed by Santander institution. It aims to study the port area of the city of Santa Fe that has been transformed into a leisure and tourism complex following an international trend of waterfronts spaces reconfiguration. The methodology involves literature review and semi-

\footnotetext{
${ }^{1}$ Doutoranda do Programa de Pós-Graduação em Arquitetura e Urbanismo da Universidade de São Paulo (IAUUSP). Mestre em Políticas Públicas pelo Programa de Pós Graduação em Serviço Social pela Universidade Federal do Pará (UFPA). Bacharel em Turismo pela Universidade Federal do Pará (UFPA). Especialista em Docência no Ensino Superior em Turismo pela Universidade Federal do Pará (UFPA).

Professora da Faculdade de Turismo da Universidade Federal do Pará (UFPA). Belém, Pará, Brasil. E-mail: francafarah@gmail.com
} 
structured interview near to the urban planning department of the city. The results show that the port area in 2004 has undergone a reconversion process of its functions, aiming to serve a policy strategic planning of the city, in search of the resumption of the centrality role. At the ending is drawn a reflection about the posture taken by public managers in the contemporary city and the weight for the tourist activity as a development bias local economic. The port reconversion in Santa Fe is based on an international model of urban planning and use of spaces in waterfronts for leisure and tourism purpose, made possible through of partnership between the public and private sectors.

Keywords: Space; Urban planning; Port area; Waterfront; Leisure and tourism.

\section{Resumen}

Este artículo es el resultado de una etapa realizada en el año 2014 en la Universidad Nacional del Litoral, en la ciudad de Santa Fe, en Argentina, en asociación con la Universidad de San Pablo y la financiación de la institución de Santander. Tiene como objetivo, el estudio de la zona portuaria de la ciudad de Santa Fe, que fue transformada en un complejo de ocio y turismo después de una tendencia internacional de reconfiguración de espacios waterfronts (frente de las aguas). La metodología de investigación bibliográfica y la aplicación de entrevistas con la secretaría de planificación urbana en la ciudad. Los resultados indican que la zona portuaria en el año 2004 pasó por un proceso de conversión de sus funciones, destinado a la atención a una política de planificación estratégica de la ciudad en busca de la reanudación de la función de la centralidad. En su extremo se perfila una reflexión acerca de la postura adoptada por los gestores públicos en la ciudad contemporánea y el peso de la actividad turística, mientras que el sesgo del desarrollo económico local. La reconversión de instalaciones portuarias en Santa Fe se basa en un modelo internacional de planificación urbana y uso de los espacios en los frentes de agua para fines de ocio y turismo, gracias a la colaboración establecida entre los sectores público y privado.

Palabras clave: Espacio; planeamiento urbano; La zona portuaria; Frente de las aguas; Elocio y el turismo.

\section{Introdução}

No ano de 2004 o Conselho Municipal aprovou o projeto do Plano Diretor desenvolvido pelas autoridades portuárias, referente à proposta de requalificação do porto de Santa Fé na Argentina. Neste Plano Diretor, apresentou uma subdivisão área portuária em seis setores, com destinações diferenciadas: Administração; comércio; institucional financeiro; residencial; lazer; turismo. Uma área foi destinada exclusivamente a manutenção das atividades portuárias. Consequentemente, foi criado um distrito administrativo chamado cidade Porto.

Este artigo reflete sobre as propostas do poder público na cidade de Santa Fé - Argentina para o planejamento urbano local, focando na área portuária, que foi reconfigurada para dar lugar a 
um complexo de lazer e turismo. A escolha por este lócus de investigação, ocorreu espontaneamente, durante entrevista realizada com o Secretário de Planejamento Urbano da cidade de Santa Fé Sr. Eduardo Navarro, no mês de outubro de 2014, que teve como tema: "Espaço público, lazer e turismo". Ao término, foi possível observar, a grande ênfase dedicada à reconfiguração da área portuária, sob a justificativa de que este espaço sofreu um processo dedecadência de suas funções durante o século XIX, sendo necessário tal intervenção para a dinamização da econômica local.

A intervenção humana no espaço, conduz a constantes modificações, pois constrói, reconfigura, cria novas centralidades, além de dinamizar economicamente e através de relações sociais. Neste sentido, a ação antrópica resulta na constituição de espaços diferenciados na cidade e com múltiplas funções, dentre elas o lazer e o turismo.

As cidades turísticas são mais valorizadas por visitantes e investidores, quando encontram-se associadas à qualidade paisagística ambiental. Neste contexto, é possível incluir as antigas zonas portuárias que foram reconfiguradas, para fins de lazer e turismo, tendo este processo, se iniciado no fim da década de 50 nos Estados Unidos onde foram identificadas as primeiras intervenções em frentes de água urbana, com especial destaque aos casos de Baltimore e de Boston. Posteriormente, as cidades da América do Norte e da Europa ocidental, iniciam na década de 80 , os seus projetos de reconfiguração das áreas portuárias, com fins de lazer e turismo, ganhando destaque internacional em termos de experiência de projetos de frentes de água. (SILVA, 2004).

Com base no exposto, a (re) produção espacial será tratada a partir da reconversão do Porto Ribera, em Santa Fé - Argentina enquanto espaço de lazer e turismo destinado a dinamização econômica local, estando associado a imagem de cidade dinâmica, desenvolvida e atraente aos novos investidores internacionais. Ao seu término é traçada uma reflexão sobre a postura assumida pela gestão pública urbana e o peso destinado a atividade turística enquanto viés de desenvolvimento econômico local, sem contudo, objetivar o esgotamento desta discussão.

\section{Alguns Aspectos do Lazer e Turismo}

A história do turismo é marcada por um acontecimento no ano de 1840, na Inglaterra, primeiro país a passar por uma industrialização efetiva, quando Thomas Cook decidiu organizar uma viagem de trem a um congresso que tinha como tema, o combate ao alcoolismo. Com a 
satisfação gerada no seu público, Cook decidiu abrir a primeira agência de viagens no mundo (ANSARAH, 2001). Vale ressaltar, que o início das viagens organizadas, está demarcada na história, juntamente com o processo de industrialização das cidades, uma vez que, com o advento da era industrial, houve um avanço significativo nos meios de transportes, favorecendo maior conforto e redução de tempo entre a origem e o destino dos viajantes.

De acordo com a Organização Mundial do Turismo - OMT a atividade turística intensificou o seu processo de expansão, a partir da 1950, em decorrência das melhorias na economia mundial, impulsionada por mais avanços tecnológicos, refletidos não somente no setor de transporte, mas igualmente, na construção civil, através dos meios de hospedagem.Desde então, as ações governamentais, tem destinado preocupação no pensar o planejamento urbano das cidades, em sintonia com as necessidades das demandas turísticas.

A qualidade na oferta turística é um dos fatores preponderantes no êxito do turismo nas cidades, onde vários elementos compõem esta oferta. Neste sentido, cabe uma conceituação do termo: Conjunto de produtos turísticos e serviços postos à disposição das demandas num determinado destino, para seu desfrute e consumo. (OMT, 2001). "A oferta turística representa o comportamento individual dos produtos (empresas e agentes que produzem o produto que se vende no setor turístico)". (LAGE e MILONE, 2003, p.163).

Quanto ao aspecto conceitual do turismo, considera-se que o mesmo é o resultado de atividades realizadas por pessoas durante as suas viagens e estadas em lugares distintos ao de seu entorno habitual, por um período de tempo consecutivo inferior a um ano, com finalidade de lazer, negócios e outros (OMT, 1998). Vale ressaltar, que se trata de uma atividade dinamizadora, não somente da economia, mas igualmente, do espaço, da paisagem, da cultura, lazer, sociabilidade, entre outros fatores que decorrem de sua existência.

Nas discussões sobre turismo, observa-se uma constante presença do termo lazer, sendo este, algo intrínseco, uma vez que as viagens são propiciadoras de prazer, naqueles que as realizam. A palavra lazer tem origem do latim licere, que significa ser permitido, surgindo nas civilizações greco-romanas, em oposição ao trabalho, que surgiu do latim, tripalium, significando instrumento de tortura. A palavra negócio, tem origem do latim nec-otium, significando nada de ócio. Com isso é possível perceber a relação contraditória e ao mesmo tempo dialética existente entre: lazer, trabalho e lucro. Ambas coexistem em uma mesma sociedade, igualmente contraditória e dialética. 
O estudo científico do lazer só teve impulso com Joffre Dumazedier (1978) considerado o pai da sociologia do lazer, que resgata o ideal grego de Scholé, ao falar em tempo de lazereducação, porém com a diferença de que hoje o tempo livre destinado ao lazer não é mais proporcionado pelo trabalho escravo, mas pela redução das jornadas de trabalho. Dumazedier compreende o lazer dentro de uma perspectiva funcionalista, onde o mesmo possui três funções principais ou 3Ds: Descanso (reparador das deteriorizações físicas e nervosas provocadas pelas tensões do trabalho e da vida cotidiana); Divertimento (recreação e entretenimento. Poderá ser um fator de equilíbrio, um meio de suportar as disciplinas e as coerções necessárias à vida social. Daí a busca de uma vida de compensação e de fuga por meio do divertimento e da evasão); e Desenvolvimento (desenvolver a personalidade, a participação social maior e mais livre). Dumazedier (1978) compreende o lazer a partir da variável Tempo: livre do trabalho e das obrigações familiares, sociais, políticas, etc.

É um conjunto de ocupações às quais o indivíduo pode entregar-se de livre vontade, seja para repousar, seja para divertir-se, recrear-se e entreter-se ou, ainda para desenvolver sua informação ou formação desinteressada, sua participação social voluntária ou sua livre capacidade criadora após livrar-se ou desembaraçar-se das obrigações profissionais, familiares e sociais. (DUMAZEDIER, 1978, p.34).

Dumazedier não considera como lazer nem o trabalho nem as obrigações familiares, nem as sócio-políticas, nem as sócio religiosas. Nesta definição a recreação é função do lazer.

O lazer é um tempo no qual o indivíduo tem o direito social de expressar a si mesmo, por si mesmo, muito mais do que nas condutas institucionalizadas, isto é, no trabalho, conjunto das obrigações familiares, sócio-política, necessárias ao governo da cidade e às atividades sócio-religiosas necessárias ao exercício do culto institucional. Mas nenhuma sociedade no mundo pode deixar um setor de suas atividades sem nenhum controle social porque é a porta aberta para a delinquência, para o roubo das coisas alheias, para o parasitismo, etc. (DUMAZEDIER, 1979, p.59).

Como é possível perceber, neste conceito, o lazer é entendido em contraposição ao tempo de trabalho, apresentando uma função reparadora das forças perdidas durante a produção. Segundo o mesmo autor, o lazer não é ativo ou passivo e que essa distinção é dependente da atitude que o indivíduo assume. Assim, tanto a prática, quanto o consumo, poderá ser ativo ou passivo, dependendo dos níveis de participação das pessoas envolvidas. Níveis esses, que podem ser classificados em elementar, caracterizado pelo conformismo, médio, onde prepondera a criticidade, e superior ou inventivo, quando impera a criatividade. 
Contudo, é importante ressaltar, que o lazer está diretamente associado às escolhas pessoais e ao prazer, sendo, portanto subjetivo. Logo, não deve existir a distinção entre lazer passivo e ativo, pois todo lazer, envolve opções, bem como diferentes níveis de satisfações ao seu término.

Marcellino (2002) considera que existem barreiras diversas que dificultam certas práticas de lazer, dentre elas as econômicas e sociais. No modo de produção capitalista, o tempo tornouse mercadoria valiosa sendo impossível o desperdício, pois tempo é dinheiro. O tempo do homem tornou-se artificial, cronometrado, onde desde o momento em que acorda até o momento de dormir encontra-se preenchido por atividades. O tempo mercadoria orienta a sociedade capitalista, fazendo com que o lazer se transforme em consumo e ostentação, onde profissionais de diversas áreas se especializam a fim de melhor captar demandas de trabalhadores com dinheiro para pagar pela ocupação prazerosa de seus tempos. Os meios de comunicação de massa apresentam um leque de opção, a preços variados.

Neste contexto, observa-se que as discussões que permeiam o conceito de lazer são amplas e variadas, não havendo consenso na forma de entendê-lo.

Aqui, o lazer é compreendido enquantocultura, atrelada às variáveistempo e atitude, existindo nas diversas esferas da vidahumana.

Cultura vivenciada no tempodisponível, nãoemcontraposição, masemestreitaligaçãocom o trabalho e as demaisesferas de obrigações da vidasocial, combinando os aspectostempo e atitude, no valor da atuação no plano cultural, numa perspectiva 'gramsciana', como instrumento de mudança social, e na crítica à visão 'funcionalista' do lazer, à concepção 'utilitarista' da educação. (MARCELLINO, 1995, p. 59).

Na sociedade contemporânea, são observadas mudanças significativas no que tange o valor do lazer, tanto por parte de estudiosos quanto pela sociedade, que vem reconhecendo neste, uma possibilidade para desenvolvimento humano, através de convivências interpessoais, conhecimento dos direitos e deveres do cidadão.

O lazer enquanto direito do cidadão, direito de intervir na definição de diretrizes que garantam tanto o acesso à participação, quanto à criação cultural colaboradora para humanização dos homens e da cidade, mediante a apropriação, a consolidação e a inauguração de novos direitos que perfazem a condição da cidadania (CAVALEIRO e SALGADO, 1996, p.103).

Os estudiosos do lazer ainda não chegaram a uma única forma de entender o seu significado e conceito, talvez não sendo inclusive fator primordial, pois as concepções diferentes 
enriquecem cada vez mais o entendimento deste campo de estudo e as diferentes visões e concepções têm contribuído para que os estudiosos interpretem o fenômeno lazer de forma a proporcionar um amplo entendimento, sem ter um modelo ou conceito exato.

\section{O Uso das Frentes de Água para Fins de Lazer e Turismo na Cidade}

O espaço urbano tem sido alvo de intervenções permanentes, em especial quanto à apropriação e uso do solo, refletidas em novas construções e reconfiguração de espaços na cidade. Discutir o espaço significa compreender a sua complexidade e inter-relação com o social, econômico e ambiental, onde a dinamicidade das transformações é uma constante. Neste contexto, o espaço segundo Santos, (2008), seria definido como uma realidade relacional, fruto do trabalho humano, ao mesmo tempo em que é geográfico, por ser determinado pelo movimento da sociedade.

O espaço não é nem uma coisa nem um sistema de coisas, senão uma realidade relacional: coisas e relações juntas. 'Eis por que sua definição não pode ser encontrada senão em relação a outras realidades: a natureza e a sociedade, mediatizadas pelo trabalho'. (SANTOS, 2008, p.28).

De acordo com Carlos (2013, p. 99) "O espaço urbano tomado como mercadoria faz com que o seu acesso seja determinado pelo mercado imobiliário". Neste sentido, observa-se que novos usos e funções foram destinadas ao espaço, estando este associados à melhoria da imagem da cidade que é trabalhada como um fator determinante no que tange aos interesses do mercado imobiliário.

A produção do espaço é resultado da ação dos homens agindo sobre o próprio espaço através dos objetos, naturais e artificiais. Cada tipo de paisagem é a reprodução de níveis diferentes de forças produtivas, materiais e imateriais, pois o conhecimento também faz parte do rol das forças produtivas (SANTOS, 2008, p.71).

Portanto, esta produção, atende às necessidades de autoexpressão humana, ao mesmo tempo em que gera conflitos de interesse, quanto às suas formas de uso e apropriação. Neste sentido, considera-se que, a forma espacial das cidades sofreu alterações nos últimos anos, sob influência dos acontecimentos na política, na economia mundial e principalmente, pelo urbanismo. Neste contexto, cabe a especificação do termo.

O urbanismo, que se toma como ciência e técnica do espaço, constitui a mediação necessária para transformar o já produzido em novo momento de reprodução do capital, uma vez que ele comporta um discurso e uma política sobre o espaço, a partir do Estado, abrindo a possibilidade de maior 
integração entre o capital financeiro e o 'imobiliário' e a produção de 'uma nova cidade', e - ou 'um novo centro' ou de uma nova cidade de eventos'. O urbanismo se converte, assim, em estratégia para garantir o processo de reprodução, num movimento que vai da expropriação à valorização imobiliária, sendo, portanto, um dos fundamentos da segregação. (ALVAREZ 2013, p.115).

É possível identificar nesta conceituação, que o espaço é tratado enquanto lócus permanente de poder e disputas, onde o urbanismo, enquanto técnica e ciência, apresenta-se como instrumento e diretriz às ações, servindo a interesses divergentes.

De acordo com Harvey (1980), o crescimento e desenvolvimento do sistema urbano impactam diretamente a distribuição de renda e a disponibilidade e mudanças de preços dos recursos que é calculado tendo como base a sua acessibilidade e vizinhança, considerando os estabelecimentos ao seu entorno. O valor dado ao solo nas cidades tem aumentado consideravelmente nas últimas décadas, principalmente quando localizados em áreas centrais e após passar por processos de reconfiguração.

O solo e suas benfeitorias são, na economia capitalista contemporânea, mercadorias. Mas, o solo e as benfeitorias não são mercadorias quaisquer: assim, os conceitos de valor de uso e valor de troca assumem significado em uma situação mais do que especial (HARVEY, 1980, p. 135).

Dentre os ajustamentos urbanos, considera-se que há uma intensificação dos projetos de requalificação de antigos espaços centrais, sob a justificativa de perda de suas funções produtivas e inutilidade. (LEITE, 2007). Politicamente esses ajustamentos refletem dinâmica da produção urbana, tendo em vista que existe uma estreita relação entre os valores do solo, o valor da moradia e o preço dos recursos, ocasionando uma capitalização irracional (HARVEY, 1980).

Neste contexto é possível perceber, o papel assumido pelo porto na cidade, onde até a segunda metade do século XIX, era considerado como o centro geográfico, em decorrência de sua funcionalidade. A partir daí, as suas funções sofreram reflexos das crises econômicas mundial, conduzindo a um processo de reconfiguração dessas áreas para aproveitamento de sua qualidade paisagística de frente de água urbana, associada em muitos casos, a fins de comércio e prestação de serviços, como por exemplo, lazer, turismo e gastronomia.

A arquitetura e o turismo em cidades turísticas desempenham papel fundamental na cenarização do espaço. Construindo elementos culturais atrativos, representam um campo de atuação tanto do mercado quanto do poder público para o projeto e o planejamento de ações estratégicas para o desenvolvimento do turismo. (SILVA, 2004, p.39). 
Nesta situação, a arquitetura industrial das antigas áreas portuárias é utilizada para fins turísticos, contribuindo para a consolidação da imagem de cidade de frente de águas. Neste sentido, cabe a conceituação de frentes de água:

As frentes de água urbanas são todas as frentes de água (rios, mares, lagos ou canais) que balizam as extremidades de uma área urbana. No seu conceito devem estar todas as vertentes da vida animal e vegetal, terrestre e aquática, os usos e funções do espaço e a população que faz uso desse território (SAIRINEN e KUMPULAINENS, 2005, p.123).

Antigas áreas industriais, portuárias de comércio marítimo, pesca etc., transformaram-se em barreiras ao desenvolvimento das cidades, após o século XIX, tendo em vista à existência de espaços obsoletos situados em áreas centrais. Com o tempo, passaram a ter as suas imagens vinculadas à ilegalidade, como tráfico de drogas e prostituição. Como exemplos representativos: Union Wahrf (Bóston); InnerHarbour (Beltimore); CanaryWharf (Londres); Hafencity (Alemanha); Battery Park (Nova Iorque).

A justificativa utilizada por esses projetos de intervenção, se sustentam na depreciação da funcionalidade e imagem das antigas áreas no centro das cidades, em especial nos espaços que apresentam frente para às águas, aproveitando a qualidade paisagística e ambiental para a capitalização do solo e composição de novas centralidades. É neste contexto, que o lazer e turismo encontram-se inseridos.

Vale ressaltar que o planejamento e gestão de cidades e espaços turísticos devem primar pela conservação dos aspectos naturais do território, de forma a atender às necessidades de seus habitantes. Consequentemente, também agradará às demandas turísticas, por experiências que envolvam qualidade ambiental e paisagística. Neste sentido, considera-se que os espaços de lazer e turismo situados na área de orla urbana, construídos ou reconfigurados, são, em muitos casos, representativos em termos de imagem de cidade, por reunirem elementos ambientais e histórico-culturais.

A frente de água, como espaço de confronto/harmonização entre a cidade e natureza começa assim a ser um leimotf no planejamento urbano, presente nas visões de Le Corbusier para as frentes de água de Argel. Barcelona, Buenos Aires ou RJ, nas prominades, nos piers e passeios marítimos (cria-se um novo vocabulário de espaços públicos nas frentes de água), nas renovações de determinadas zonas nas cidades de água (a exposição do mundo português em 1940, abrindo Lisboa ao Tejo), até ao atual conceito de waterfront e suas operações de reconversão urbana. (OCHOA, 2014, p.5). 
A Espanha apresenta uma repercussão internacional no final da década de 80, ao ser eleita como cidade sede das Olimpíadas de 1992 em Barcelona. Antes deste mega evento, a cidade não estava articulada ao mar, sendo separada por uma grande via composta por 10 faixas de rolagem (Passeig de Colom). Logo, a recuperação do porto de Barcelona passou a ser uma prioridade governamental para a construção de uma imagem de cidade cosmopolita, apresentando um plano de recuperação de suas zonas portuárias, áreas industriais que impactou diretamente a imagem da cidade, dando destaque aos espaços e equipamentos de lazer ali instalados. Com intervenção, Barcelona transforma-se em uma referência mundial no modelo urbanístico de frente ribeirinha.

Ainda na Espanha, outro caso merece destaque. A maior cidade de frente atlântica do norte da Espanha - Bilbau que apresentou uma indústria naval decadente no final do século XIX, somado a problemas sociais, também requalificou a sua frente ribeirinha. Contudo, esta intervenção esteve associada a um novo contexto econômico, apesar de ambos ocasionarem um contínuo processo de gentrificação nas cidades.

De acordo com Vasconcelos, (2013) o termo gentrificação (gentry) foi criado em 1964 significando pequena nobreza, fazendo referência aos bairros habitados pela classe operários de Londres que foram ocupados por pessoas de classe média. "O que a gentrificação sempre provoca: 'é o deslocamento mais ou menos forçado de pessoas via de regra pobres, ou seja, (re) colocando em marcha em alguma medida, à segregação" (SOUZA, 2013, p.134).

Ao refletir sobre o termo gentrification a partir do dicionário Oxford American, conclui-se que a substituição de classes sociais e consequente segregação de moradores no espaço é o mais forte elemento característico. De forma geral, a gentrificação é decorrente da valorização de áreas (re) qualificadas, tendo como foco a retomada do papel de centralidade no urbano, atraindo moradores de classe média e alta que buscam a atratividade gerada pelas novas construções, como por exemplo, os espaços de lazer e turismo.

A construção de parques na cidade tem sido um dos responsáveis pela intensificação de processos de gentrificação.

Os novos parques parecem ter sido concebidos como elementos centrais de operações urbanas para provocar voluntariamente uma implacável mecânica de substituição de população, funcionando como aceleradores das mudanças no perfil social dos bairros e cidades 'requalificados'. (...). A segregação de grandes parcelas da população reforça a ideia de que, no contexto urbano contemporâneo, o parque público é antes de tudo um espaço de alto valor 
patrimonial, contrariando o senso comum que idealiza esses equipamentos como bens coletivos e lugares de diversão, do entretenimento e da natureza socializada. (SOUZA, 2013 p. 173).

Com base no exposto é possível considerar que a cidade contemporânea, passa por um contínuo processo de redefinição do papel assumido pelos seus centros, que resultam em novas estruturas de produção do urbano. A redefiniçãa de suas funções é um aspecto desafiador tanto ao poder público e iniciativa privada, que visam continuamente à inserção produtiva do capital interno e externo, garantindo desta forma a sua fluidez. "Essa diferença revela-se numa apropriação privada determinada pela distribuição da riqueza, portanto, da posse da riqueza gerada sob sua forma privada, envolvendo diferencialmente toda a sociedade" (CARLOS, 2013, p.99).

O papel assumido pelo mercado imobiliário ganha destaque, ao transformar o urbano em mercadoria, limitando o acesso à centralidade e consequentemente aos bens e serviços nela localizados. As consequências decorrentes dessa ação no urbano são inúmeras e perversas, dentre elas, cita-se a hierarquia de lugares, delimitando o uso por classes sociais, conduzindo a um encolhimento da esfera pública e uma expansão da iniciativa privada.

[...] a reprodução do espaço urbano sinaliza, em seu desdobramento, a produção da metrópole, subordinada aos interesses particulares do grande capital, delineando a tendência da submissão dos modos de apropriação do espaço urbano, portanto, o desenvolvimento (da propriedade apresenta novos usos e impõe normas objetivas). (CARLOS, 2013, p.103).

A (re) produção do espaço urbano pensada sob o viés da construção e ou requalificação de espaço, apresenta uma forte preocupação com o embelezamento, revelados através de projetos paisagísticos representativos de imagem de cidade. Neste sentido, as cidades que aderiram a waterfronts demonstraram similaridade no que tange a valorização paisagística e de capitalização do solo, além do intenso papel da iniciativa privada dinamizando a lógica de mercado, como é possível citar: Barcelona e Bilbao na Espanha.

Esses novos espaços urbanos que sofreram reconversão, em geral, possuem uma diversidade de atividades destinadas ao lazer, turismo, comércio e serviços. Igualmente, tal amplitude, se estende a denominação, sendo chamados: complexos ou terminais de transportes; Complexos de lazer e turismo, parques urbanos, etc.

Os lugares turísticos são, em grande parte, vendidos como cenários produzidos sobre uma base paisagística preexistente que, associada a 
aspectos culturais, históricos e geográficos, constitui a matéria-prima para o processo contínuo de produção e consumo do espaço (SILVA, 2004, p.21)

Os neoplanejadores ao compreenderem a cidade como empresas focam em produtividade e competitividade, além de subordiná-la à lógica do mercado. Neste sentido, a cidade é colocada na condição de agente econômico. Harvey utiliza a denominação de empresariamento da gestão urbana (HARVEY, 1996, apud, VAINER, 2000, p.85).

Projeto de cidade: Pátria, empresa e mercadoria. 'implica a direta e imediata apropriação da cidade por interesses empresariais globalizados e depende, em grande medida, do banimento da política de eliminação do conflito e das condições de exercício da cidadania'. (VAINER, 2000, p. 78).

Vainer (2000) considera que a transposição do modelo estratégico característico das empresas privadas para a realidade urbana, conduz a um intenso processo de competitividade e a instauração de um patriotismo. A cidade entendida como empresa a coloca na condição de um grande agente econômico que atua no âmbito de um mercado, seguindo as suas regras e diretrizes de planejamento. Logo, a imagem é trabalhada como um fator determinante no que tange aos interesses do mercado imobiliário.

Ações estratégicas são planejadas e executadas tendo como horizonte e foco primeiro, o mercado, neste sentido, pensar o planejamento urbano como se pensa o planejamento de uma empresa privada é uma questão polêmica entre as discussões críticas sobre cidade, tendo em vista os divergentes interesses envolvidos. Cabe ressaltar, que a cidade necessita ser pensada em consonância com os anseios sociais em termos de consolidação de políticas urbanísticas democráticas, que contemplem primeiramente as necessidades dos habitantes locais, haja vista que uma cidade boa para mora, também impactará na experiência dos visitantes.

As políticas urbanas na contemporaneidade, não têm priorizado a conformação e reconfiguração de espaços realmente públicos, de lazer. Contrariamente, observa-se uma intensificação de projetos voltados ao atendimento dos interesses da iniciativa privada, em especial em espaços centrais e com grande valor histórico na cidade, por despertarem interesse dos visitantes e turistas, acabam por comportarem empreendimentos privados, como por exemplo, bares, restaurantes, shopping centers, hotéis, condomínios e residências.

Em decorrência deste fato, as políticas urbanas, optam, em muitos casos, pela elaboração de projetos que ignoram os anseios dos habitantes locais, por mais e melhores espaços públicos de lazer, favoráveis a sociabilidade. O equilíbrio é necessário no que tange a parceria público- 
privado, afim romper com a elaboração de políticas urbanas que tratam a cidade como um negócio.

\section{Cidade de Santa Fé - Argentina: Reconversão Portuária}

A cidade de Santa Fé na Argentina foi fundada no ano de 1573. Está localizada na província de Santa Fé, considera a de maior importância nas áreas de agricultura e pecuária no país. Estácercada pelo rio Paraná e apresenta diversos braços de rios e lagos, onde a lagoa Setúbal (Guadalupe) apresenta destaque. O seu traçado urbano respondeu ao clássico modelo quadricular adaptado pela conquista espanhola para as suas cidades e a sua ocupação dependeu do desenvolvimento de uma população que nunca ultrapassou entre 1.500 a 2.000 habitantes. (FEDELE, 2011, p. 28).

O porto assumiu papel de centralidade, pois foi transformado em parada obrigatória para registrar os navios com destino ao Paraná. Séculos seguintes ao processo de modernização da cidade de Santa Fé a questão sanitarista de higienização da cidade, emerge com força e impacta a vida local e a noção de urbanismo, vinculado agora a evolução das cidades e de suas populações. O urbanismo passa a ser pensado sob o ponto de vista do positivismo e funcionalismo, utilizando paradigmas da medicina no planejamento das ações na cidade.

Na primeira metade do século XX surge um pensamento urbanístico que enfatiza à relação do rio com a cidade, onde Angel Guido, no ano de 1927 foi responsávelpela constituição do primeiro plano urbanístico de Santa Fé. Neste plano há destaqueao papel do rio na cidade. Logo, o rio transforma-se em prioridade no planejamento urbano, que aproveitando o potencial hídrico local.

Isso porque os santafesinos se aproximavam dos rios com finalidades práticas como, por exemplo: Lavagem de roupas, pescaria, higiene corporal, coleta de água, etc. Ou recreativo, como tomar banho durante o verão. No próprio projeto da Avenida Bulevar Gálvez, Schonoor colocava estações de banho no ponto de encontro do passeio como a Ribeira da Laguna, como distração por sexo que não era comum em Santa Fé (COLLADO, 2008. Tradução nossa).

A urbanização da cidade de Santa Fé apresenta-se fortemente marcada por intervenções como o Parque Oroño e a Costaneira. Ambos constituem-se em espaços públicos de lazer que influenciaram de forma intensa o processo de reordenamento espacial com os interesses 


\section{TURISMO EM ANÁLISE}

locacionais de fixação de moradias nas áreas ao entorno.Por muitos anos consecutivos a gestão municipal em Santa Fé se ocupou com o tema das praças e áreas verdes, contudo, à medida em que a população crescia, alguns espaços foram perdendo vigência, sendo loteados e se incorporaram ao mercado imobiliário.

Outros espaços surgiram e foram incorporados à dinâmica da cidade, seguindo um processo de hierarquização, em razão da expansão da área urbanizada. Conforme os governos das cidades de Santa Fé foram se sucedendo, as mudanças quanto à prioridade destinada à ornamentação e incremento de equipamentos nas praças e parques, foram intensificadas. As obras públicas voltadas à melhoria dos espaços na cidade,apresentaram aceitação social, por serem de grande visibilidade (COLLADO, 2008).

Os espaços públicos além de modificarem paisagisticamente a cidade, possibilitaram encontros e convivências entre os seus habitantes. Espaços que ofereceram a sociedade diversão e serviços de alimentos e bebidas, bandas de música, equipamentos para atividades físicas etc. (COLLADO, 2008. Tradução nossa).

A construção de espaços de lazer no ambiente urbano não deve ser entendida de forma isolada ou espontânea, como tem se constatado em políticas de caráter reducionista. A compreensão ampla perpassa essencialmente por políticas urbanísticas que favoreçam a democratização do acesso e usufruto de espaços.

Figura 1: Cidade de Santa Fé - Argentina.

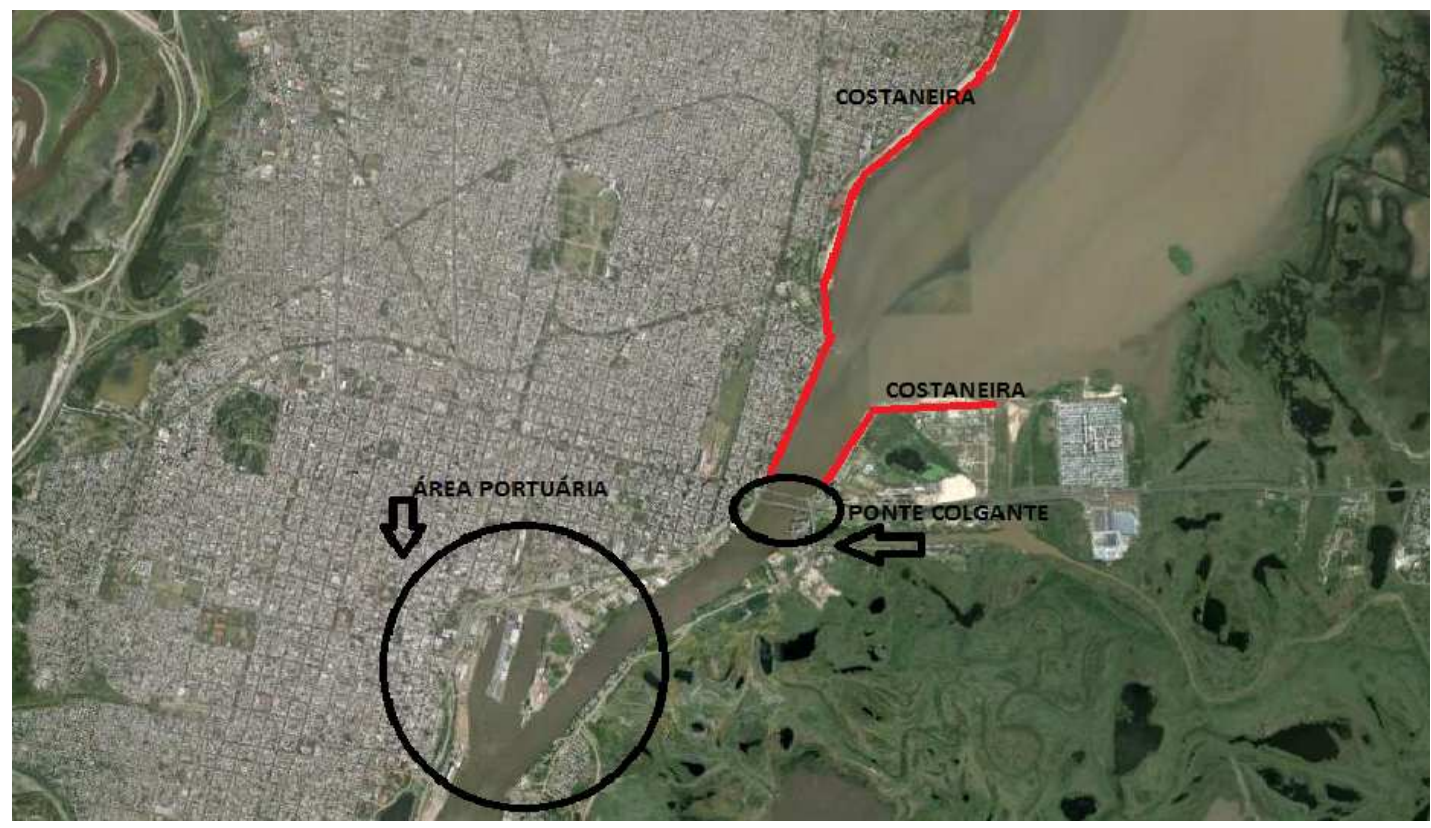

Fonte: Google Earth, 16 de junho de 2015. Adaptado pela autora. 
Neste sentido, a Avenida Costaneira, na cidade de Santa Fé, é uma grande área de Orla livre, que possibilita acesso físico e contemplativo ao rio podendo ser considerada, a materialização do espaço público urbano, por tratar-se de uma nova forma de vinculação entre o habitante e a natureza ao entorno, favorecendo ao visitante, lazer através da qualidade ambiental e contemplativa.

Fedele (2011) considera que nas últimas décadas muito se tem falado sobre a relação do rio com a cidade, em especial em grandes cidades litorâneas, que negaram por algum motivo, a presença do rio na vida cotidiana de seus habitantes. Na realidade argentina os esforços estratégicos se orientaram com maior ou menor êxito para a recuperação de áreas costeiras e destacaram as possibilidades públicas que até o presente haviam sido negadas.

Os projetos de transformação urbana nas cidades argentinas como, por exemplo, Buenos Aires, Rosário e Santa Fé se destacam por serem reflexos das mudanças na produção. Como resposta, houve uma intensificação dos processos de renovação, voltados a melhoria da imagem de cidade, agora não mais industrial. Grandes setores de ferro portuário foram repensados e incluídos na pauta das discussões públicas objetivando a rearticulação do tecido urbano com o rio.

No caso de Santa Fé a gestão local criou uma nova estratégia Urbana Portuária, visando à retomada da centralidade histórica desempenhada pelo Porto na cidade. A área portuária foi reconfigurada sob o viés de planejamento estratégico de cidades, norteadas por um modelo que se utiliza das frentes ribeirinhas como atributo para a competitividade e atração de investimentos em áreas consideradas obsoletas após o período de desindustrializaçãoocorrido no mundo após os séculos XIX e XX. Foi transformada em um grande complexo de lazer e turismo.

Complexos turísticos constituem empreendimentos turísticos comerciais planejados e constituídos exclusivamente para atender às demandas de lazer. São estruturas espaciais mais ou menos autônomas que podem, por vezes, apresentar características de assentamentos urbanos, quase como uma cidade independente (SILVA, 2004, p.84).

De acordo com entrevista cedida ao jornal El Litoral pelo administrador do Porto Ribera no ano de inauguração da área, 2008, o pleno desenvolvimento de Santa Fé envolve necessariamente, a transformação de sua área portuária, com a instalação de diversos 
empreendimentos, dentre eles: Hotel, Centro de Convenções, Cassino e Shopping Center. Um verdadeiro complexo de lazer. (EL LITORAL, 2011).

Os investidores instalados na área portuária, estão nada menos do que no principal polo de desenvolvimento urbanístico da cidade. O porto responde a uma visão estratégica, que converteu-se em uma zona de elite da cidade, por estar próxima ao centro, às avenidas, cidades vizinhas e principalmente à água e as zonas de ilhas. (VOROBIOF (Administrador do porto). Traduzido. EL LITORAL, 2011).

A iniciativa privada assume a dinâmica dos espaços, ali construídos, revelando uma apropriação do público pelo privado. Vale ressaltar, que o poder público local cedeu a concessão para a construção desses estabelecimentos, que poderão permanecer por 30 anos consecutivos.

Este exemplo de reconversão portuária pautada em uma vertente de planejamento estratégico de cidade e de espaço público revela-se como altamente condizente com a dinâmica mundial do capitalismo. A ação do mercado imobiliário, valorizando o uso do solo e resgatando centralidades, gera como principal consequência, hierarquias sócio espaciais, no que tange ao usufruto de espaços públicos de lazer. A importância do rio soma-se ao valor do solo e com isso, há uma reformulação de discursos, com forte apelo ambiental e social.

A cidade de Santa Fé é apresentada o seu Plano Estratégico como um cenário aberto a todos os sentidos, onde o rio e a natureza se unem ao ambiente urbano.

\subsection{Secretaria de urbanismo de Santa Fé: sobre a reconversão portuária}

De acordo com entrevistarealizada com o Secretário de Planejamento Urbano da cidade de Santa Fé Sr. Eduardo Navarro a fundação da cidade no ano de 1573 objetivou transforma-la na primeira cidade porto da Argentina. No século seguinte, 1640, o porto passou a ser parada obrigatória para as embarcações que circulavam no território. Em 1905 é construído um novo porto com capital do Estado, sendo inaugurado em 1911 para atendimento as demandas produtivas locais.

Nas décadas de 70 foi construído um paredão no porto santafesino, com aproximadamente 3 metros de altura que impedia a visualização do rio pela sociedade, sendo demolido apenas no ano de 2000. As atividades portuárias declinaram em função do seu baixo calado (pouca profundidade do rio Panamá, que inviabiliza o trafego de grandes navios cargueiros). Logo, o 
porto perde a sua importância estratégica e se transforma em uma "grande área ociosa", segundo o ponto de vista da administração local.

O porto de Santa Fé perdeu o seu papel econômico, passando por um processo de obsolência e perda da centralidade. A importância do porto esteve associada à segurança militar e questão estratégica econômica e governamental. Contudo, após a perda de sua funcionalidade, surge à necessidade de reconversão do espaço.

De acordo com Navarro (2014), cada avanço no território da cidade é típico de sua época. Neste sentido, tem início no ano de 2003 , o processo de reconversão portuária da cidade, através da Lei provincial sancionada. $\mathrm{n}^{\circ}$. 12.108/2003. É relevante compreender que a relação da cidade de Santa Fé com o rio é de longa data, tendo em vista que um dispositivo de defesa foi criado para a barragem do rio, na área mais pobre da cidade,com o objetivo de impedir o avanço das águas. Contudo, esta ação impossibilitou a população de acesso paisagístico às águas.

O Secretário de Urbanismo, destaca também que a cidade teve dois processos distintos de ocupação da área de orla.Uma relacionada à área Portuária, que se expandiu com fins econômicos voltando-se ao escoamento da produção e a outra diz respeito à região da Costanera que apresenta um forte laço de identidade com a população local.

A força econômica da cidade e o acesso livre da população a diferentes áreas de desfrute, com qualidade paisagística, transformam-se em questões que despertam o interesse tanto no setor privado quando do público constituindo-se em uma tarefa árdua aos planejadores governamentais ter que conciliar divergentes interesses da iniciativa privada e sociedade civil.

A proposta do Plano Diretor para a reconfiguração portuária iniciou-se em 2001 e buscou a ampla adesãoda sociedade santafesina, como forma de consolidação do projeto. A população foi esclarecida sobre a necessidade de reconversão portuária, compreendendo os seus benefícios para a dinâmica econômica local. Com isso, o poder público iniciou a construção, no território portuário, de uma área de desenvolvimento urbano.

É incorporado à área portuária um importante centro turístico e institucional para a cidade e para a província de Santa Fé, vinculado a um diversificado sistema de transporte rodoviário, ferroviário e fluvial, com um clube náutico esportivo e residencial, com importante hotelaria a partir do restauro de antigos e emblemáticos edifícios, uma moderna sede para exposições e convenções, com passeios culturais e mostras de produção regional, com um centro comercial e um setor especial de escritórios e pequenas e médias empresas, com espaços públicos para a recreação distribuídos em uma grande superfície de parques e praças (CONVERTI, 2004, p. 3) 
Como resultado do projeto de reconversão, surge o Porto Ribera. Este foi redesenhado com o objetivo de transformar-se em um complexo turístico e de entretenimento, de grande valor histórico. A sua estrutura foi composta pelos empreendimentos:Cassino Santa Fé;Los Silos Hotel;Los Maderos Centro de Convenciones;La Ribera Shopping.

Figura2: Puerto Ribera - Cidade de Santa Fé - Argentina

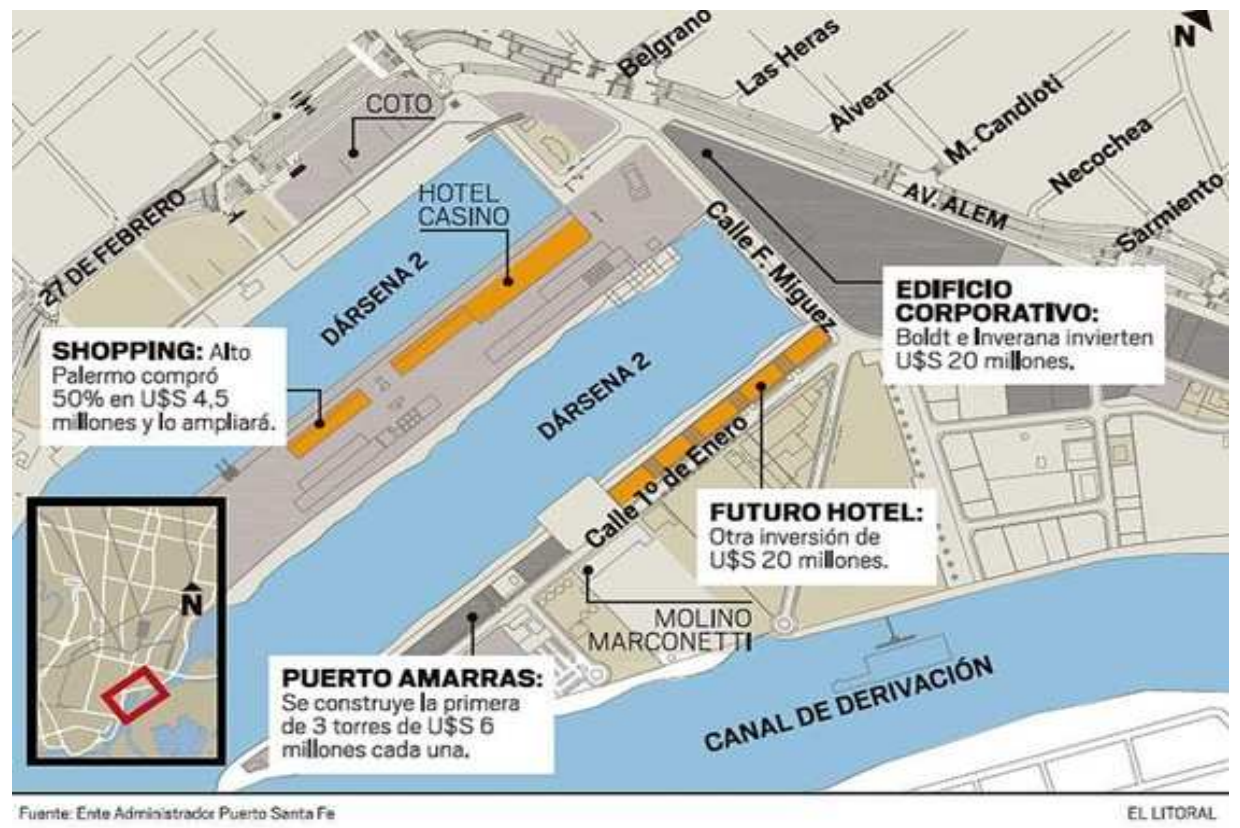

Fonte: Porto de Santa Fé apud jornal El Litoral, 2011.

É realizado um parcelamento da área portuária a partir de um plano específico para o desenvolvimento urbano, convertendo o espaço, em área urbana, igual ao ocorrido em diversas cidades do mundo. Esta divisão objetivou a garantia de acesso populacional às áreas adjacentes ao rio. De acordo com entrevista junto a Secretaria de urbanismo, a lei municipal estabeleceu à integração de um "percentual significativo" da área portuária à cidade, retirando grande parte de sua função operacional. Definiu a altura máxima, metro quadrado possível por terreno, por parcela, liberação de solo, que porcentagem do espaço seria público ou privado, o que poderia ser construído, etc.(NAVARRO, 2014)

O Estado acima citado, neste estudo, se materializa na figura da Secretaria de Santa Fé que cede espaço para ação do mercado em um grande território público, que é a área portuária. Nesta área, foi construído um complexo de lazer e turismo, onde os setores empresariais envolvidos receberam a concessão da terra para uso,por no máximo de 30 anos. "É uma 
espécie de aluguel com contrato estabelecendo tempo e formas de uso, por isso não são donos". (NAVARRO, 2014).

Figura 3: Área portuária da cidade de Santa Fé.

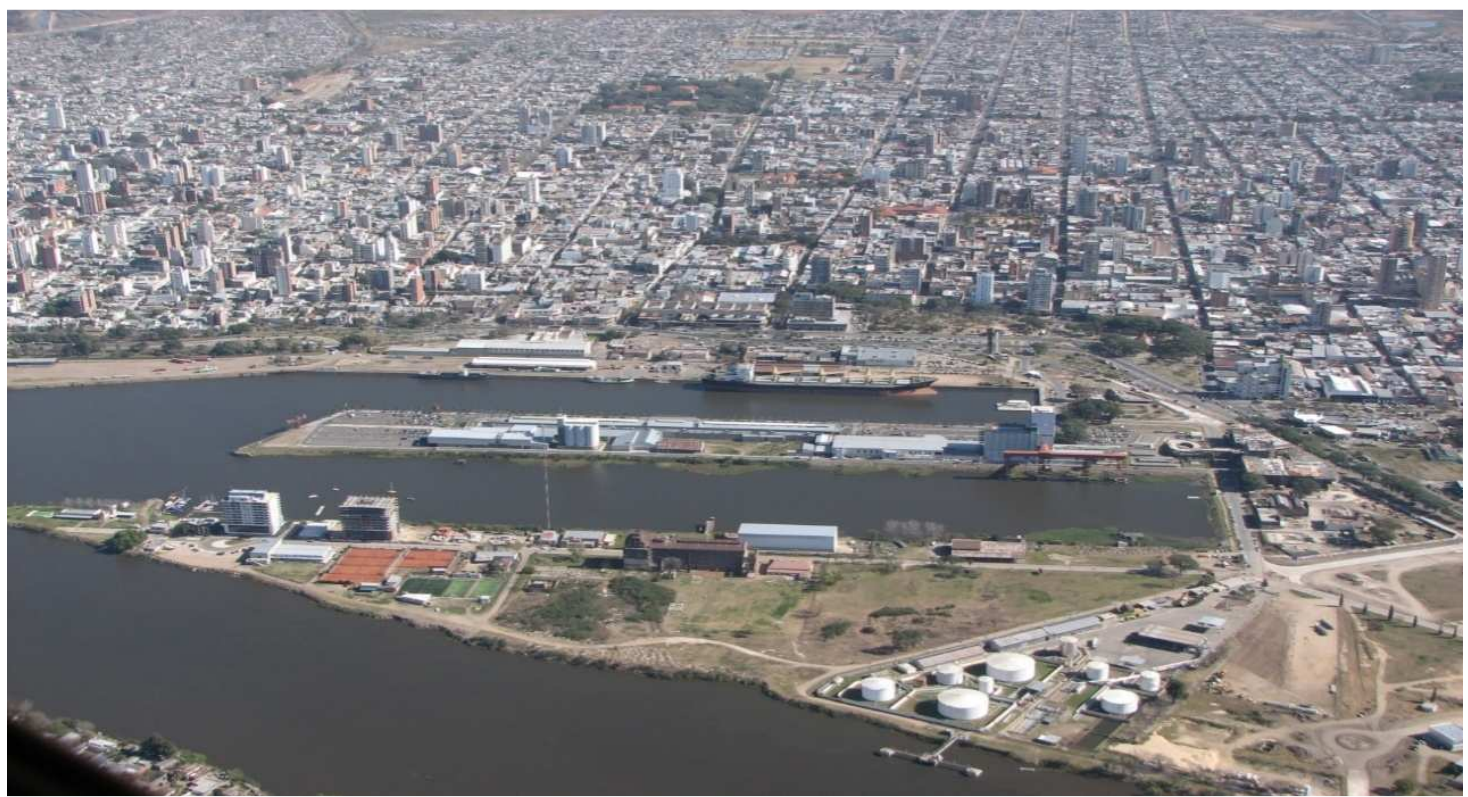

Fonte: Secretaria de Urbanismo de Santa Fé, 2014 (material disponibilizado em pen drive).

Navarro (2014) ressalta ainda que: "O espaço público democrático é um processo lento orientado por leis sobre o público e privado". "O crescimento econômico é desordenado na cidade, daí a necessidade de um planejamento urbano que permitirá uma reorientação das ações no território, mudando e corrigindo o cenário da cidade".

O secretário, acredita ainda, quea atual gestão por pensar antecipadamente o território, permitiu a equipe de trabalho da Secretaria transformar o planejamento em uma ferramenta de consenso, onde, discussões e debates foram fomentados com a população nas ruas para discutir o plano portuário e sugerir alterações. Diversas questões foram debatidas com a sociedade, dentre elas a gestão do solo, terra, do patrimônio histórico, questão imobiliária, cultura e turismo. A flexibilidade neste processo de planejamento foi marcante, colaborando de sobremaneira para a modificação do contexto vivido pela cidade e seus habitantes.

Segundo Navarro, a cidade de Santa Fé é bem ordenada em seu traçado urbano, sendo este um fator positivo, que ajudou e tem ajudado bastante à gestão atual. O tecido da cidade é ordenado, possuindo uma estrutura urbana bem organizada, com avenidas e ruas. Do ponto de vista social a cidade também apresenta aspectos positivos segundo avaliação governamental. 
A tendência à transitoriedade da terra não gera qualidade, pois as ações são pontuais e frágeis. Isto é uma questão apresentada pela sociedade, que também possui livre acesso as áreas abertas do porto. "Neste espaço, o fluxo de pessoas a passeio é pequeno, pois não possui uma estrutura física propiciadora. Mas é aberto a todos!” (NAVARRO, 2014).

Durante a entrevista, percebe-se é nítida o entendimento de planejamento urbanoassociado à economia urbana, ao tratar de questões pertinentes gestão urbana de espaços e ações. $\mathrm{Na}$ economia urbana não se pode dizer sempre não. "Pois quando se fecha um lugar à gestão urbana tem que abrir outros lugares para a inserção da iniciativa privada, pois é ela quem gera emprego e dinamiza a cidade". (NAVARRO, 2014). Pensar em alternativas viáveis é uma questão importante.

Neste sentido, observou-se que a gestão urbana de Santa Fé, tem apostado na construção e reconversão de espaços como meio de gerar trabalho e fomentar a economia, buscando o atendimento dos interesses do setor empresarial. O caso da reconversão portuária foi apresentado pela secretaria,com maior ênfase, por ser este, um projeto de destaque, dentre as suas ações no ambiente urbano local.

\section{Considerações Finais}

O homem historicamente tem produzido e reproduzido o ambiente urbano, utilizando em muitos momentos, modelos, considerados exitosos, de planejamento e gestão do espaço, em busca de alternativas para a resolução de seus problemas.

Na sociedade contemporânea,considera-se que o poder público compreende a cidade,a partir de modelos de gestãoque priorizem à atração de investimentos e condições de competitividade, com especial beneficiamento à iniciativa privada. Neste contexto, o turismo, enquanto atividade econômica e social, ao atuar como fator disseminador da imagem de cidade, enquanto lócus de atrativos naturais, históricos, culturais, de lazer e eventos, acaba por compor os planos governamentais, servindo como meio de viabilizar estratégias de desenvolvimento.

No caso da reconversão portuária do Porto Ribera em Santa Fé, os empreendimentos turísticos se destacam, através de espaços, como, hotel, cassino e shopping center. Tudo isso, associado a uma frente de água urbana, considerada como um elemento diferencial, favorável 
à atratividade e competividade. Uma nova perspectiva de centralidade é criada ao entorno deste complexo, despertando o interesse dos investidores, em especial, do mercado imobiliário.

Vale ressaltar, que as teorias sobre produção e reprodução do espaço urbano, consideram que o capital organiza e regula o espaço com o apoio do Estado. Isso significa dizer que, o urbano se tornou refém dos interesses privados, em especial do mercado imobiliário, através de um modelo de gestão sob a denominação de planejamento estratégico que busca incessantemente o consenso social como forma de respaldo às suas ações no espaço urbano contemporâneo, o mesmo ocorre com a ênfase na parceria pública - privado.

Este tipo de discurso-ação foi identificado durante a entrevista com o Secretário de Urbanismo da cidade de Santa Fé e no material bibliográfico sobre a reconversão portuária local. É possível identificar que, existe um conhecimento avançado dos gestores públicos sobre teorias e métodos para melhoria do planejamento e gestão de cidades, sem, contudo, atingir o âmbito efetivo das ações. Estão presentes nesses discursos, o modismo através de palavras como cidadania, desenvolvimento sustentável, participação (busca do consenso) e da responsabilidade social.

Outro fator preocupante é a redefinição do papel de centralidade e as formas utilizadas para alcança-la, tendo em vista os processos de segregação por ela ocasionados. A busca pela retomada da centralidade, tem gerado uma hierarquização do urbano e de seus espaços, dentre eles, os espaços destinados ao lazer e turismo, como parques e áreas em frentes de água. Neste sentido, a compreensão da reconfiguração urbana da área portuária de Santa Fé revela que o poder público local, tem trabalhado, seguindo um modelo de planejamento estratégico em busca de uma retomada produtiva deste espaço em comum acordo com a iniciativa privada, através da concessão de uso do espaço por empreendimentos comerciais, em grande parte, voltados a atividade turística.

O turismo, neste contexto, assume um papel de importância, enquanto atividade econômica com potencial efeito multiplicador, favorável à geração de empregos e atração de investimentos.

Dentro do espaço portuário, as áreas livres destinadas a livre circulação, são na verdade brechas, sem nenhuma infraestrutura favorável ao lazer gratuito. Ou seja, após a construção 
do hotel, cassino e shopping, quase nada restou em termos de área livre para o usufruto coletivo. Cabe refletir sobre a privatização do espaço público, em situações como esta.

O Porto de Santa Fé, compreendido com espaço público requalificado para fins privados, fruto de um Plano Diretor Urbano, revela ser coerente com outras experiências internacionais, dentre elas Barcelona e Bilbau no que se refere à retomada do papel da centralidade após a fase de obsolência de seus períodos industriais.

O turismo enquanto atividade dinamizadora da economia local vem compondo a pauta de discussões políticas e planos urbanísticos das cidades pelos gestores públicos e iniciativa privada, que priorizam os espaços localizados em frentes de água (waterfronts). O interesse em reconfiguração de antigas áreas portuárias é um fato presente em muitas cidades, repetindo-sena realidade de Santa Fé, que tem almejado a renovação de sua imagem, atrelando-a ao turismo. Contudo, a crítica que se faz a esta experiência, está relacionada a ênfase dedicada ao fator econômico, em detrimento do enfoque social. Ou seja, a reconfiguração portuária primou pelo benefício ao setor empresarial e valorização imobiliária da área ao entorno. Com isso, foi omisso no que tange a produção social, possível de ser desenvolvida a partir do turismo, afim de evitar a intensificação de processos de gentrificação.

O lazer e o turismo pensados no cotidiano das cidades,devem estar diretamente vinculados à sociabilidade e à integração com às práticas rotineiras da população local, sendo de essencial importância, refletir sobre o alcance dos projetos urbanos, questionando se os mesmos possibilitam uma apropriação dos espaços públicos pelos cidadãos ou se a preocupação é somente em transformar a cidade em um grande negócio.

\section{Referências}

ALVAREZ, Isabel Pinto. A segregação como conteúdo da produção do espaço urbano. In: VASCONCELOS, Pedro de Almeida; CORREA, Roberto Lobato; PINTAUDI, Silvana Maria (orgs). A cidade contemporânea: Segregação Espacial. SP: Contexto, 2013.

ANSARAH, M. G. dos R. (Org.) Turismo, como aprender como ensinar. Vol. 2. São Paulo: Senac, 2001.

CARLOS, Ana Fani A. A Prática Espacial Urbana Como Direito À Cidade: Como Horizonte Utópico. In: VASCONCELOS, Pedro de Almeida; CORRÊA, Roberto Lobato; PINTAUDI, Silvana Maria (Orgs). A cidade contemporânea: Segregação Espacial. SP: Contexto, 2013.

CAVALEIRO Maria Cristina; SALGADO, Marilene. Diadema: Direitos que vamos construindo. In: Políticas públicas setoriais de lazer: o papel das prefeituras, 1996. 
COLLADO, Adriana. Modernización urbana en ciudades provincianas de Argentina: teorías, modelos y prácticas. Director: Juan Luis Piñón PallarésTese de Doutorado Defendida na Universidad Pablo de Olavide de Sevilla, Espanha, Janeiro, 2008.

CONVERTI, Roberto. Santa Fé Argentina: Uma Estratégia Cidade - Porto. Disponível em:<www.vitrovirus.com.br-revistaaquitextos. 2004>.Acesso: 26 Abr.2015.

DUMAZEDIER, Joffre. Questionamento teórico do lazer. Porto Alegre: Centro de Estudos de lazer e recreação, Pontifícia Universidade Católica do Rio Grande do Sul, 1978.

. Sociologia empírica do lazer. São Paulo: Perspectiva, 1979.

EL LITORAL. Uma zona em pleno desarrollo.Edição do Domingo 13 de novembro de 2011.

FEDELE, Javier. El río em laciudaddelPlan. Santa Fé: Universidad Nacional del Litoral. 2011.

HARVEY, David. A justiça social e a cidade. SP: Hucitec, 1980.

LAGE, Beatriz Helena Gelas; MILONE, Paulo Cesar Fundamentos multidisciplinares do turismo: economia do turismo. p. 151-176. In: TRIGO, Luiz Gonzaga Godoi. Turismo, como aprender como ensinar. Vol. 1. São Paulo: Senac, 2003.

LEITE, Rogério Proença. Contra usos da cidade: Lugares e Espaços Públicos na experiência urbana contemporânea. SP: Unicamp - Editora: UFS, 2007.

MARCELLINO, Nelson Carvalho. Lazer e humanização. Campinas: Papirus, 1995.

Estudos do lazer: uma introdução. $3^{\circ}$ Ed. Campinas, SP: Autores associados, 2002.

OMT. Introduccíon al turismo. Madrid, 1998.

OMT - Organização Mundial do Turismo. Introdução ao turismo. São Paulo: Roca, 2001.

SAIRINEN, R.; KUMPULAINENS S. Assessing Social Impacts in Urban Waterfront Regeneration, in: Environmental Impact Assement Review. n. 26, ed. Elsevier, 2005, p. 120-135.

SILVA, Maria da Glória Lanci da. Cidades Turísticas: Identidade e Cenários de Lazer. São Paulo: Aleph, 2004.

SANTOS, Milton. A natureza do Espaço: Técnica e tempo, razão e emoção. 4ed. 4 reimpressão. SP: USP, 2008.

SOUZA, Marcelo Lopes de. Semântica Urbana e Segregação: Disputa simbólica e embates políticos na cidade empresarialista. In: VASCONCELOS, Pedro de Almeida; CORREA, Roberto Lobato; PINTAUDI, Silvana Maria (orgs). A cidade contemporânea: Segregação Espacial. SP: Contexto, 2013.

VAINER, Carlos B. Pátria, empresa e mercadoria. Notas sobre a estratégia discursiva do planejamento estratégico Urbano. In: ARANTES, Otília et al. A cidade do pensamento único: Desmanchando consensos. 3. ed. Petrópolis: Vozes, 2000.

VASCONCELOS, Pedro de Almeida; CORREA, Roberto Lobato; PINTAUDI, Silvana Maria (orgs). A cidade contemporânea:Segregação Espacial. SP: Contexto, 2013.

Mapa das províncias Argentinas. Disponível em: 〈http://www.avesargentinas.org.ar/coa/〉. Acesso em: 14 Jun. 2015.

\section{Recebido em: $21 / 06 / 2015$ ( $1^{\mathrm{a}}$ versão) $27 / 06 / 2016$ ( $2^{\mathrm{a}}$ versão)}

\section{Aprovado em: 28/07/2016}




\section{Apêndice}

\section{Roteiro de Entrevista Semiestruturada}

Entrevistado: Eduardo Navarro - Secretário de Planejamento Urbano de Santa Fé.

Local: Cidade de Santa Fé - Argentina

Data: $30 / 10 / 2014$

1. Qual a Proposta de Gestão da Secretaria de Planejamento Urbano vinculada ao lazer e turismo para Cidade de Santa Fé? Destacar os principais projetos de intervenção na cidade.

2. Como a Região do Porto está sendo Planejada e Gerida pela Secretaria?

3. Como a Secretaria de Planejamento atua na gestão de espaços públicos de lazer, como por exemplo, a Costanera?

OBS: Entrevista gravada e transcrita. 